\title{
Assessment of coronary wall thickening in autosomal dominant hyper- immunoglobin E syndrome (AD-HIES) using TRAPD-MRI
}

\author{
Khaled Z Abd-Elmoniem", Nadine Ramos', Saami Yazdani ${ }^{3}$, Steven Holland ${ }^{2}$, Alexandra Freeman², \\ Ahmed M Gharib ${ }^{1}$
}

From 19th Annual SCMR Scientific Sessions

Los Angeles, CA, USA. 27-30 January 2016

\section{Background}

Autosomal dominant hyper-IgE (AD-HIES), also called Job's syndrome, is a rare primary immunodeficiency caused by dominant mutations in STAT3. AD-HIES is characterized by elevated levels of IgE, an ineffective immune response to several infectious agents, and connective tissue and arterial abnormalities. To date, coronary artery evaluation in AD-HIES patients has been limited to lumenography by CTA or MRA. Direct in vivo coronary vessel wall imaging may allow for earlier detection of coronary artery disease, possibly at the subclinical stage, and may lead to more accurate assessment of treatment efficacy.

The goal of this prospective study was to evaluate the coronary artery walls of AD-HIES patients using MRI and compare to healthy subjects and subjects with known coronary artery disease.

\section{Methods: study population}

A total of 28 subjects were included in the study; 10 subjects with AD-HIES, 8 healthy subjects, and 10 patients with with known CAD as proven by coronary Computed Tomography Angiography (CTA). Groups were age- and BMI-matched as shown in the table.

\section{Coronary wall imaging}

free-breathing time-resolved dark-blood (trapd-mri) proximal coronary vessel wall datasets were acquired with a fixed inversion time ( $\mathrm{TI}=200 \mathrm{~ms}$ ) and phase-sensitive reconstruction. Data were acquired using a segmented kspace spiral acquisition with spectral spatial excitation,

${ }^{1} \mathrm{NIDDK}, \mathrm{NIH}$, Bethesda, MD, USA

Full list of author information is available at the end of the article using a 32-channel phased array cardiac received coil and VCG triggering. Images were anonymized, wall thickness was measured as previously published.

\section{Computer tomography angiography}

Multidetector computerized tomography (MDCT) scans with ECG gating were performed in 10 CAD subjects. The MDCT protocol was similar to previously described techniques. Image analysis and interpretation of the axial and the multiplanar re-formatted images were performed using a commercial three-dimensional software tool.

\section{Results}

Examples of the coronary vessel wall images in the three groups are shown in Figure 1a. MRI imaging of coronary vessel walls of AD-HIES patients showed thicker vessel walls than those of healthy controls (Table 1 ). There was no statistically significant difference in vessel wall thickness between non-AD-HIES subjects with atherosclerosis and AD-HIES patients (Figure 1b).

\section{Conclusions}

This is the first study to image the coronary vessel wall of patients with AD-HIES by MRI. The MR vessel thickness of AD-HIES patients was compared to both healthy subjects and patients with known coronary artery disease (CAD) as demonstrated by CTA. The findings demonstrate that the coronary vessel wall in Job's syndrome subjects is thicker than healthy subjects, however, comparable to patients with known CAD. These findings suggest that coronary arteries in Job's syndrome are affected with atherosclerosis, contrary to prior beliefs and study findings. 


\begin{tabular}{|c|c|c|c|c|}
\hline & \multicolumn{4}{|c|}{ Characterization of Study Participants } \\
\hline & & AD-HIES $(n=10)$ & CAD $(n=10)$ & Normal $(n=8)$ \\
\hline & \multicolumn{4}{|c|}{ Mean (SD) } \\
\hline & Age (years) & $30( \pm 14.7)$ & $31( \pm 12.7)$ & $46( \pm 8.7)$ \\
\hline & Systolic BP(mmHg) & $121.0( \pm 11.8)$ & $116.2( \pm 14.2)$ & $125.5( \pm 10.8)$ \\
\hline & Diastolic BP(mmHg) & $72.0( \pm 10.4)$ & $72.0( \pm 7.6)$ & $74.3( \pm 6.2)$ \\
\hline & BMI $\left(\mathrm{kg}^{2} / \mathrm{m}^{2}\right)$ & $24.9( \pm 3.4)$ & $26.5( \pm 2.8)$ & $25.8( \pm 4)$ \\
\hline & $\begin{array}{l}\text { Vessel Wall } \\
\text { Thickness }\end{array}$ & $1.4( \pm 0.05)^{*}$ & $1.3( \pm 0.05)$ & $1.1( \pm 0.06)^{*}$ \\
\hline & Lumen Area & $9.8( \pm 2.02)^{\wedge}$ & $4.8( \pm 2.02)^{\wedge}$ & $6.1( \pm 2.3)$ \\
\hline & \multicolumn{4}{|c|}{$\begin{array}{l}\text { *^p values were significantly less than } 0.05 \text {. } \\
\text { *Vessel wall thickness significantly thicker in Job's compared to normal controls but similar to patients with } \\
\text { known CAD. } \\
\text { ^Lumen area significantly dilated in Job's compared to CAD patients but slightly larger than NL without } \\
\text { statistically significant difference }\end{array}$} \\
\hline Figure 1 & & & & \\
\hline
\end{tabular}

(a) Right Coronary Artery 3T MRI Image

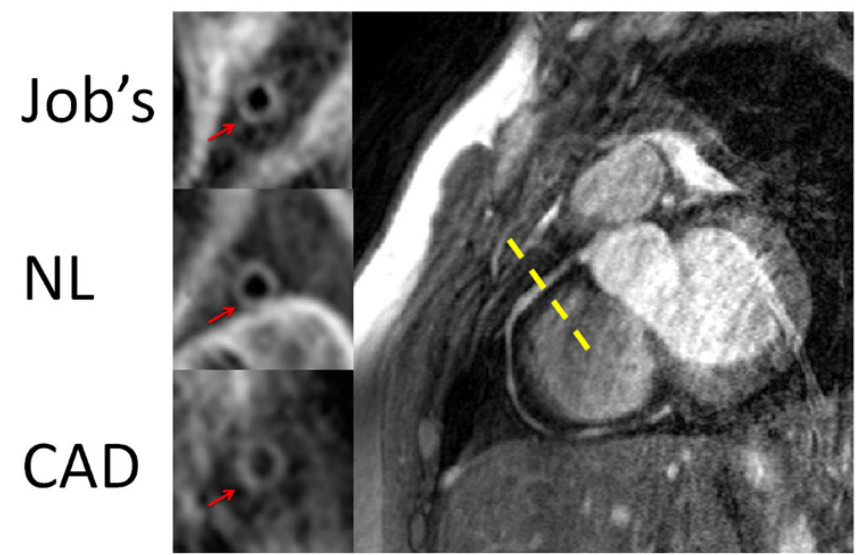

(b) Coronary Artery Wall Thickness Across Three Groups

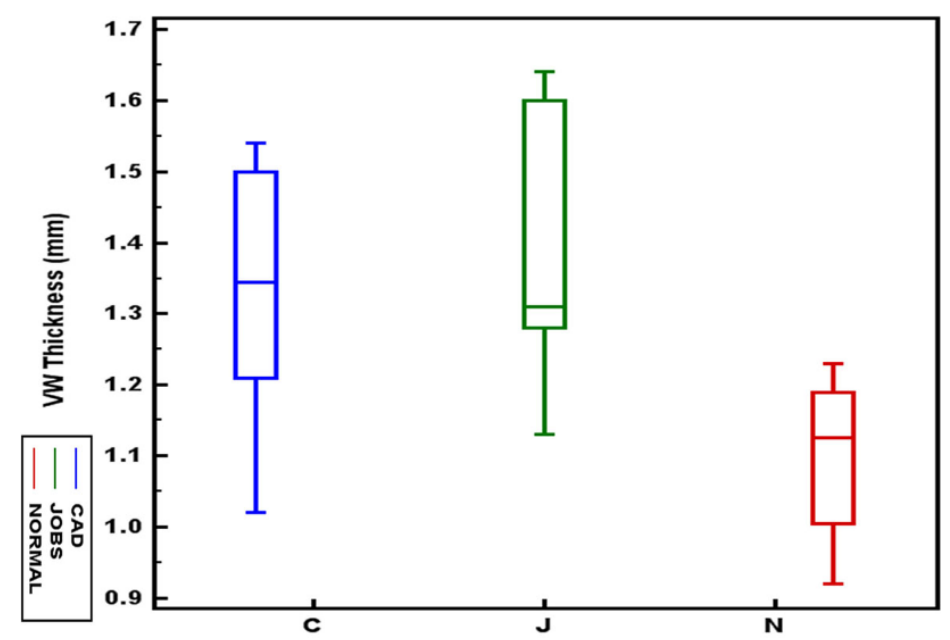

Figure 2 


\section{Authors' details}

${ }^{1} \mathrm{NIDDK}, \mathrm{NIH}$, Bethesda, MD, USA. ${ }^{2} \mathrm{NIAID}, \mathrm{NIH}$, Bethesda, MD, USA. ${ }^{3}$ University

of South Alabama, Mobile, AL, USA.

Published: 27 January 2016

\section{Reference}

1. Abd-Elmoniem KZ, et al: Coronary vessel wall 3-T MR imaging with timeresolved acquisition of phase-sensitive dual inversion-recovery (TRAPD) technique. Radiology 2012, 265(3):715-723.

doi:10.1186/1532-429X-18-S1-05

Cite this article as: Abd-Elmoniem et al: Assessment of coronary wall thickening in autosomal dominant hyper- immunoglobin $E$ syndrome (AD-HIES) using TRAPD-MRI. Journal of Cardiovascular Magnetic Resonance 2016 18(Suppl 1):05.

Submit your next manuscript to BioMed Central and take full advantage of:

- Convenient online submission

- Thorough peer review

- No space constraints or color figure charges

- Immediate publication on acceptance

- Inclusion in PubMed, CAS, Scopus and Google Scholar

- Research which is freely available for redistribution

Submit your manuscript at www.biomedcentral.com/submit
C Biomed Central 